\title{
Post Operative Systolic Pressure Ratio between Right and Left Ventricle Predicts Early Outcome after Total Correction of Tetralogy of Fallot
}

\author{
A.T SHAHRIER AHMED, MD. KAMRUL HASAN, MD. REZAUL KARIM \\ Dept. of Cardiac Surgery, National Institute of Cardiovascular Diseases (NICVD), Dhaka, Bangladesh \\ Address of Correspondence: Dr. AT Shahrier Ahmed, Assistant Register, Department of Cardiac Surgery, NICVD, Dhaka \\ E-mail:profkamrulcts@gmail.com
}

\begin{abstract}
:
$P_{R V L V}$ can be easily measured in the operating room by which we can assess the adequacy of relief of pulmonary stenosis. A number of studies carried out where PRV/LV ratio 0.7 was taken as cut off point however in this study post repair ratio 0.5 was taken as cut off value because a recent study has shown better outcome after total correction of tetralogy of Fallot when the post repair PRV/LV was below.05. When the ratio is above 0.5 , some extra precaution may be needed in the post operative period to reduce the morbidity and mortality.
\end{abstract}

Kev words: Tetralogy of Fallot, PRV/LV ratio, low output syndrome.

University Heart Journal 2017; 13(2): 59-61

\section{Introduction:}

Congenital heart disease is the commonest of all congenital lesions. The incidence of congenital heart disease is approximately 6-8 per 1000 live birth. World Health Organization reports, among all cardiovascular disease, the incidence of congenital heart disease in Bangladesh is $6 \%$. Tetralogy of Fallot (TOF) is the most common cause of cyanotic congenital heart diseases. The post repair right ventricular and left ventricular peak systolic pressure ratio $\left(\mathrm{P}_{\mathrm{RV} / \mathrm{LV}}\right)$ is related to residual right ventricular outflow tract obstruction (RVOTO), pulmonary arteriolar resistance and size of pulmonary arteries. It is a risk factor for death early and late after operation. It is reported that risk of death approach about $50 \%$ when post repair ratio is equal to or more than 0.8 . The $\mathrm{P}_{\mathrm{RV} / \mathrm{LV}}$ ratio is measured to ensure that significant residual outflow tract obstruction does not exist. If the post-operative $\mathrm{P}_{\mathrm{RV} / \mathrm{LV}}$ ratio is in excess of 0.7 then a transannular patch should be inserted across the pulmonary valve annulus. If the ratio is still high then the causes of persistent elevation of right ventricular pressure must be considered. The post repair $\mathrm{P}_{\mathrm{RV} / \mathrm{LV}}$ ratio is a measure of residual pressure gradient between the right ventricle and the distal pulmonary arteries. Residual RV outflow tract or pulmonary trunk obstructions, small diameter of left and right pulmonary arteries, residual stenosis at the origin of pulmonary arteries, peripheral pulmonary stenosis, incomplete arborization of pulmonary arteries contribute to elevation of post repair $\mathrm{P}_{\mathrm{RV} / \mathrm{LV}}$ ratio.

Materials \& Methods:

Type of study: Prospective Observational Study.

Place of study: Department of Cardiac-surgery, National Institute of Cardiovascular Diseases (NICVD)

Period of study: July, 2012 to June, 2014.

\section{Study population:}

All the patients undergoing total correction of tetralogy of Fallot at NICVD during the given period were the study population. Patients were selected according to inclusion and exclusion criteria irrespective of age and sex.

\section{Sampling Techniques:}

Purposive convenient sampling.

Selection of Patients:

Inclusion Criteria:

Patients diagnosed as Tetralogy of Fallot planned for primary total correction irrespective of age and sex.

\section{Exclusion Criteria:}

- Tetralogy of Fallot with absent pulmonary valve syndrome.

- Tetralogy of Fallot with major aortopulmonary collateral arteries. 
- Tetralogy of Fallot with other anomaly (Atrioventricular canal defect, Aortic stenosis, Mitral stenosis).

- Patients with a prior systemic-pulmonary artery shunt.

- Tetralogy of Fallot with coronary artery anomalies.

Sample size calculation:

Sample size for each group was 27 and Sample size of this study was 54 .

\section{Grouping of the patients:}

Patients were divided into two groups according to the post-operative PRV/LV ratio .Group - A (Post-operative PRV/LV ratio < 0. 5) and Group - B (Post-operative PRV/ $\mathrm{LV}$ ratio $>0.5$ )

\section{Variables:}

A. Demographic variables: Age, Sex, body weigh

B. Pre-operative investigative variables: Haematocrit, Percent saturation of oxygen (SpO2), Electrocardiogram, $\mathrm{Z}$ value for pulmonary valve annulus, RVOT-PA gradient.

C. Per-operative variables: PRV/LV pressure ratio before and after repair, Trans-annular patch required/ not required, Cardiopulmonary bypass Time (minutes), Aortic cross-clamp time (minutes).

D. Post-operative outcome variables: Ventilation time (hrs), Duration of inotrope support, ICU stay (hrs), Low output syndrome, Arrhythmia, Reintubation Renal dysfunction, Pleural effusion. Respiratory complication, Wound infection, Mortality

E. Variables at discharge from hospital and follow up: RVOT-PA gradient, Pulmonary regurgitation and its severity, Right ventricular dysfunction and its severity, Mortality (within 30 days).

\section{Result:}

Age distribution of the patients between two groups were almost similar with mean ages of Group-A and Group-B being $9.95 \pm 4.51$ and $8.89 \pm 5.01$ years respectively $(p=0.590)$. the sex distribution between two groups which was almost similar. The difference was not statistically significant between two groups. $(p=0.273)$. Mean body weight of the group A and group B were $20.03 \pm 7.89$ and $19.40 \pm 8.79 \mathrm{~kg}$ respectively The difference was not statistically significant between two groups $(\mathrm{p}=0.783)$. mean $\mathrm{SpO} 2$ were $85.00 \pm 5.14$ and $82.70 \pm 5.48$ in group $\mathrm{A}$ and group B respectively. The mean hematocrit (Hct) values were $48.46 \pm 4.60$ and $46.87 \pm 4.15$ respectively.
The difference was not statistically significant between two groups. Mean "Z" values for Pulmonary valve annulus $(\mathrm{P}-\mathrm{V})$ of group A and group B were $-2.95 \pm 0.81$ and $-3.22 \pm 0.84$ respectively $(\mathrm{P}=0.238)$. Mean RVOTPA pressure gradients of group A and group B were 75.33 \pm 13.20 and $80.40 \pm 13.81$ respectively $(\mathrm{P}=0.174)$. There is no difference in $\mathrm{CPB}$, aortic cross clamp time, transannular patching $(\mathrm{P}=0.256,0.84,1.00)$. After repair both the groups exhibited reduction of $\mathrm{PRV} / \mathrm{LV}$ pressure ratio, but the reduction was significantly higher in GroupA than Group-B $(0.45 \pm 12$ vs. $0.32 \pm 17, \mathrm{p}=<.001)$. The mean ventilation time of group A and group B were 11.30 \pm 3.27 and $13.93 \pm 5.93$ hrs respectively. The difference was statistically significant between two groups $(\mathrm{P}=0.049)$. 51.85\% patient of group $\mathrm{B}$ and $18.51 \%$ patient of group A required prolonged duration of inotropic support. The difference was statistically significant $(p=0.01)$. The patients of Group-B after operation stayed longer in the ICU than those of GroupA $(83.55 \pm 13.83$ vs. $78.85 \pm 12.55)$ though it is statistically not significant $(\mathrm{p}=0.196)$. A significantly higher proportion of patients in Group-B exhibited low output syndrome (LOS) compared to those of Group-A (33.33\% vs. $7.40 \%, p=0.018)$. Arrhythmia, renal dysfunction, pleural effusion, wound infection, respiratory complication and reintubation, were all identically distributed in both groups $(p>0.05)$. One patient of group A and two patients of group B expired in post-operative period. RVOT-PA gradient, Incidence of pulmonary insufficiency, right ventricular dysfunction of the patients at discharge and 1 month after discharge was not statistically significant between groups.

\section{Discussion:}

The demographic variables were almost identically distributed between group A and group B. Preoperative investigative variable were identical between two groups. Peroperative variable like CPB, aortic cross clamp time, transannular patching were almost similar between two groups but After repair both the groups exhibited reduction of $\mathrm{PRV} / \mathrm{LV}$ pressure ratio, but the reduction was significantly higher in Group-A than Group-B $(0.45 \pm 12$ vs. $0.32 \pm 17, p=<001)$. The difference between mean ventilation time of group A and group B were not statistically significant. 11 patient of group B and 5 patient of group A required prolonged duration of inotropic support. The difference was statistically significant $(p=0.01)$. The patients of Group-B after operation stayed longer in the ICU than those of GroupA though it is statistically not significant $(\mathrm{p}=0.196)$. The incidence of low output syndrome was more in group B $(\mathrm{P}=0.018)$ this results reflect that $\mathrm{PRV} / \mathrm{LV}$ ratio is associated with increased incidence of early adverse 
outcome. Other in hospital morbidity were almost similar between two groups.

\section{Conclusion:}

For drawing concrete conclusion, a large number of patients should be included in the study and both short and long term follow up is necessary, considering all the facts and figures found in this study following conclusion can be drawn:

The results of complete repair of TOP in the present study show acceptable morbidity, mortality and overall clinical outcome at early follow-up. The presence of low cardiac out, prolonged inotropic support and prolonged ventilation time were significantly associated with postoperative PRV/LV ratio of more than 0.5 . So early diagnosis and management of the possible presence of low cardiac output will reduce post-operative mortality and morbidity. Further studies will be necessary to ascertain an appropriate postoperative PRV/LV ratio as our protocol, based on adequately relieving RVOT, minimizing postoperative pulmonary insufficiency and ventricular dysfunction.

\section{References:}

1. Alexiou, C., Mahmoud, H., Khaddour, A. A., Gnanapragasam, J., Salmon, A. P., Keeton, B. R. and Monro, J. L. Outcome After Repair of Tetralogy of Fallot in the First Year of Life, the Annals of thoracic Surgery, 2001;71:494-500.

2. Atik, F.A., Atik, E., Cunha,C.R.D., Caneo, L.F., Assad, R.S., Jatene, M.B., Riso, A.and Marcial, MB. Long-term results of correction of tetralogy of Fallot in adulthood, European Journal of Cardiothoracic Surgery, 2004;25:250-55.

3. Bertranou, E.G.,Thibert, M. and Aigueperse, J. Short term variations of the right ventricular/left ventricular pressure ratio following repair of tetralogy of Fallot, Annals of Thoracic Surgery, 1983;71:427-29.

4. Blackstone, E.H., Kirkling, J.W., Bertranou, E.G., Labrosse, C. J., Soto, B. and Bargeron, L.M. Preoperative prediction from cineangiograms of post repair right ventricular pressure in tetralogy of Fallot, the Journal of Thoracic and Cardiovasular Surgery, 1979;78(4:542-52.

5. Chittithavorn, V., Rergkliang,C., Chetpaophan,A., Vasinanukorn, P., Sopontammarak, S. and Promphan, W. Predicted outcome after repair of Tetralogy of Fallot by post operative pressure ratio between right and left ventricle, Journal of Medical Association of'Thailand,yol. 2006;89(1):43-50.

6. Murphy, J.G., Gersh, B.J., Mair, D.D, Fuster, V., McGoon, M.D., Ilstrup, D.M., McGoon, D.C., Kirklin, J.W.and Danielson, G.K. Longterm outcome in patients undergoing surgical repair of tetralogy of Fallot, The New England Journal Medicine, 1993;329(9):593-99.

7. Nollert, G., Fischlein, T., Bouterwek, S., Bohmer, C., Klinner, W. and Reichart, B. Long-term survival in patients with repair of tetralogy of Fallot : 36- year follow-up of 490 survivors of the first year after surgical repair, Journal of the American College of Cardiology, 1997;30(5):1374-83. 